\title{
SOEP
}

SOEPpapers

SOEPpapers
on Multidisciplinary Panel Data Research

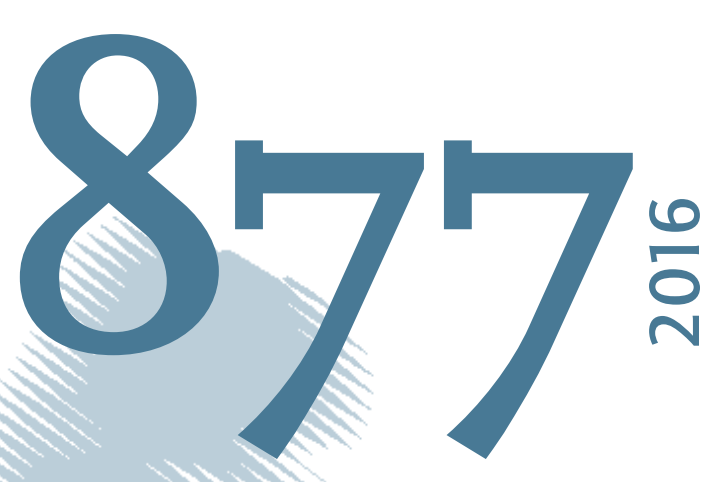

\section{Heterogeneity in Price Responsiveness for Residential Space Heating in Germany}


This series presents research findings based either directly on data from the German SocioEconomic Panel study (SOEP) or using SOEP data as part of an internationally comparable data set (e.g. CNEF, ECHP, LIS, LWS, CHER/PACO). SOEP is a truly multidisciplinary household panel study covering a wide range of social and behavioral sciences: economics, sociology, psychology, survey methodology, econometrics and applied statistics, educational science, political science, public health, behavioral genetics, demography, geography, and sport science.

The decision to publish a submission in SOEPpapers is made by a board of editors chosen by the DIW Berlin to represent the wide range of disciplines covered by SOEP. There is no external referee process and papers are either accepted or rejected without revision. Papers appear in this series as works in progress and may also appear elsewhere. They often represent preliminary studies and are circulated to encourage discussion. Citation of such a paper should account for its provisional character. A revised version may be requested from the author directly.

Any opinions expressed in this series are those of the author(s) and not those of DIW Berlin. Research disseminated by DIW Berlin may include views on public policy issues, but the institute itself takes no institutional policy positions.

The SOEPpapers are available at http://www.diw.de/soeppapers

\section{Editors:}

Jan Goebel (Spatial Economics)

Martin Kroh (Political Science, Survey Methodology)

Carsten Schröder (Public Economics)

Jürgen Schupp (Sociology)

Conchita D'Ambrosio (Public Economics, DIW Research Fellow)

Denis Gerstorf (Psychology, DIW Research Director)

Elke Holst (Gender Studies, DIW Research Director)

Frauke Kreuter (Survey Methodology, DIW Research Fellow)

Frieder R. Lang (Psychology, DIW Research Fellow)

Jörg-Peter Schräpler (Survey Methodology, DIW Research Fellow)

Thomas Siedler (Empirical Economics, DIW Research Fellow)

C. Katharina Spieß (Education and Family Economics)

Gert G. Wagner (Social Sciences)

ISSN: 1864-6689 (online)

German Socio-Economic Panel (SOEP)

DIW Berlin

Mohrenstrasse 58

10117 Berlin, Germany

Contact: soeppapers@diw.de

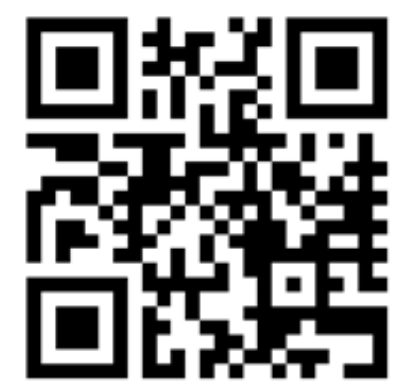




\title{
Heterogeneity in Price Responsiveness for Residential Space Heating in Germany
}

\author{
Hendrik Schmitz, Reinhard Madlener ${ }^{\dagger}$ \\ Institute for Future Energy Consumer Needs and Behavior (FCN) \\ School of Business and Economics / E.ON Energy Research Center \\ RWTH Aachen University \\ Mathieustrasse 10, 52074 Aachen, Germany
}

(also published as FCN Working Paper 05/2015)

This version: November 2016

\begin{abstract}
Space heating and hot water expenditures make up the majority of household energy demand in Germany, at 83.2\%, making them an attractive target for energy policies. Using a panel dataset derived from yearly residential household surveys covering the years 1996 to 2014, we identify the determinants of heating expenditures for German households. We discover significant heterogeneity in expenditures depending on socioeconomic variables. For the full sample, we find a price elasticity of heating expenditures of 0.629 . Elasticities vary significantly between individual groups, with values ranging from 0.523 to 0.716 . Furthermore, a large number of technical and socio-demographic factors are significant in determining energy use. Our findings have implications for evaluating the effectiveness of policy measures that aim at influencing energy use across different groups of consumers.
\end{abstract}

JEL classification: C23, D12, Q41

Keywords: Germany, Heating demand, Heating expenditures, Heterogeneity, Space heating.

*E-Mail: hschmitz@eonerc.rwth-aachen.de, corresponding author.

${ }^{\dagger}$ E-Mail: rmadlener@eonerc.rwth-aachen.de 


\section{Introduction}

Space heating and hot water preparation remain two of the major components of total energy consumption in Germany. In 2013, 25.6\% of final energy use in Germany was consumed by private households (excluding transport). $83.2 \%$ of this usage was allotted to space heating $(66.8 \%)$ and hot water $(16.4 \%)$, which by far outweighs all other uses such as cooking, ICT, lighting, or cooling (BMWi, 2016). These numbers highlight the significant impact space heating has on overall energy consumption and subsequently on residential greenhouse gas emissions. Understanding the determinants of residential energy consumption is therefore highly relevant for the design and evaluation of policy measures that aim at curbing energy use. This is especially true when considering the ambitious goals set by the German Federal Government. Germany has made a commitment to cut primary energy consumption by $20 \%$ until 2020 and by 50\% until 2050, compared to the base year 2008 (BMWi, 2015).

In this paper, we provide micro-econometric evidence on the heterogeneous factors that drive the demand for space heating of different socio-economic groups. We explore the heterogeneity between groups with a number of methods. Specifically, we use interaction terms, quantile regression, and mean clustering to derive our results. We find evidence for heterogeneity in price responsiveness for socio-economic factors such as income and age. On the other hand, technical variables such as building age and type do not lead to significantly different elasticities across groups.

There is a number of studies that focus on space heating using household level data. Schuler et al. (2000) model energy demand for space heating in (West) Germany; they analyze data from a household survey from 1988 containing around 44,000 observations. The authors find that building characteristics are an important factor in determining energy use, while socio-economic factors can only explain a small part of the energy use of households in the sample.

Rehdanz (2007) uses data from the German Socio-Economic Panel (SOEP) to investigate space heating and hot water preparation expenditures for German households for the years 1998 and 2003. Across seven different specifications, the author reports a significant influence of a range of technical and socio-economic variables on households' expenditures for heating. Using the most recent edition of the same data source, we extend our analysis to the years from 1996 to 2014. This allows us to use panel methods and additionally evaluate the existence and magnitude of heterogeneity in price responsiveness between different groups.

Another relevant study that models heating expenditures, using panel data from Great Britain, is Meier and Rehdanz (2010). Similarly to Rehdanz (2007) and our own study, the authors examine the influence of socio-economic and technical characteristics on the expenditures for space heating per room. However, they do not look into possible heterogeneity in price responsiveness between different groups. More recently, Lange et al. (2014) explore the relationship between environmental attitudes and heating expenditures in Great Britain. They find that while environmental behaviors and habits are associated with lower heating energy consumption, environmental attitudes and perceptions are not.

For the Netherlands, Brounen et al. (2012) exploit cross-sectional data from 2007 covering more than 300,000 owner-occupied dwellings. They consider both gas and electricity consumption regardless of end use. While they disregard price changes as a possible influence on energy consumption, the authors find most of the variables included to be statistically significant. Most notably, these include type, size and age of the dwelling as well as number 
of household members, occupants' age and income. Projecting their results into the future, they conclude that the increasing aging of the Dutch population alone could easily offset the savings of a possible home insulation program. This finding underlines the importance of socio-demographic factors in the analysis of energy demand.

The vast majority of studies estimating price and income elasticities in the context of consumer energy demand focuses on obtaining the mean elasticity, which is then assumed to be valid for all households. However, this ignores the possibility of significant heterogeneity between different groups of households that cannot be captured by estimating a mean effect for the entire population. For example, low income households might have significantly different price elasticities compared to more affluent ones due to several factors such as satiation for high income households or the lack of access to substitutes for low income consumers. Exploring the heterogeneity in energy demand by means of econometric modelling, which has not been done before, can help to better understand the underlying economic mechanisms that determine energy behavior and design more targeted energy-saving policies.

In space heating, heterogeneity in price elasticities between groups can manifest itself in a variety of ways. For instance, richer households might exhibit weaker reactions to price changes if they already reached their desired level of utility from thermal comfort. Then, consuming more energy for heating would not increase utility, even if prices were to fall (Galassi and Madlener, 2016). Furthermore, split incentives between landlords and tenants might affect the heating behavior of the latter compared to homeowners. Given that the share of homeowners in Germany is only $52.6 \%$, differences in heating behavior between owners and tenants are of particular interest. ${ }^{1}$

In the context of space heating, our study is the first to investigate heterogeneity in price responsiveness by socio-demographic and socio-economic characteristics. However, there is a small number of papers aiming at explaining the existence and magnitude of heterogeneity in gasoline demand, utilizing a variety of methods. Wadud et al. (2010) explore heterogeneity in gasoline demand using household level panel data for the US. Using a random effects model with a translog specification, the authors discover heterogeneity by interacting both price and income with a number of demographic variables. The authors find that price elasticities decrease in magnitude with increasing income, meaning that wealthier households react less strongly to price changes. Furthermore, income elasticities are found to be lower for higher income households, possibly because households with higher income levels are already near satiation.

Frondel et al. (2012) provide further evidence for heterogeneous reactions to price changes for private car travel in Germany. In attempting to explain heterogeneity in direct rebound effects, which can be explained through price elasticities, the authors employ quantile regression on a rich set of panel data. They find significant differences in price responses of drivers in different quantiles. Specifically, the price elasticity is lower in magnitude for households that drive more, whereas consumers who have very low demand for private car travel react more strongly to price changes. While the authors also interact fuel prices with different demographic variables, they do not find any of the interaction terms to be statistically significant, contradicting the findings from Wadud et al. (2010).

Gillingham (2014) and Gillingham et al. (2015) derive estimates for vehicle-miles-traveled (VMT) in private transport with respect to gasoline prices in the US. The authors explore heterogeneity in demand response by using quantile regression, splitting the sample into

${ }^{1}$ Home ownership in Germany is lower than in any other EU country, with an average rate across the EU-28 of $70.0 \%$, Source: Eurostat/SILC (2015). 
subgroups, interacting the gasoline price variable with demographic factors, and conducting k-means clustering. Both studies find significant heterogeneity between groups regarding their price and income elasticities.

Our research question is twofold. Firstly, we want to examine what determines household expenditures for space heating, with a focus on price and income elasticities. Our data set allows us to consider technical factors as well as social characteristics and attitudes in our analysis. Following from this, we investigate possible heterogeneity in price elasticities between different groups of consumers, which we identify by utilizing quantile regression, using interaction terms, and splitting the data into appropriate subsamples using k-means clustering. We use a long-running panel study for Germany, using annual data from 1996 to 2014 comprising more than 30,000 households in total. For the full sample, we find a price elasticity of expenditures for heating ranging from 0.577 to 0.672 across specifications, which is equivalent to a price elasticity of demand between -0.328 and -0.423 . Additionally, we uncover evidence for significant heterogeneity in price responsiveness between household groups.

The remainder of this article has the following structure: Section 2 presents the methodology employed for our estimations and the dataset used, which we extend from a variety of sources. Section 3 discusses the results obtained in light of our main research questions. Firstly, we present the results for our main regressions on the full sample, which helps to explain the drivers of residential heating expenditures. Secondly, we investigate the heterogeneity of price responsiveness between household groups applying several methods. Section 4 concludes and suggests avenues for future research.

\section{Data and Model}

\section{$2.1 \quad$ Data}

We utilize data from the German Socio-Economic Panel (SOEP), a panel survey conducted yearly by the German Institute for Economic Research (DIW Berlin). Initiated in 1984, this survey uses questionnaires to gather representative micro-level data on German households regarding their economic, social, and demographic situation. ${ }^{2}$

Each individual in the sample who is at least 17 years old is being questioned to assess individual characteristics including level of education, detailed job history, and political preferences. Furthermore, the household head fills out an additional questionnaire with questions regarding household-specific characteristics such as the size of the dwelling, appliance stock or the total household income. A separate set of survey questions is answered by the household head for each child living in the household.

Since one of the goals of the survey is to allow for long-term observations, the same participants are being interviewed every year. To mitigate attrition caused by interviewees opting out or passing away, and in order to maintain the representative nature of the survey, additional samples are being drawn irregularly, usually every three to five years. At the same time, people moving out of a sample household (e.g. due to divorce or children leaving their parents' home) remain in the sample as a new household. Non-sample people who move into a SOEP household are also included in all subsequent iterations of the survey. ${ }^{3}$

\footnotetext{
${ }^{2}$ Similar panels from other countries include the PSID (US), BHPS (UK), SLID (Canada), and HILDA (Australia)

${ }^{3}$ For a more thorough description of the SOEP panel, see Wagner et al. (2007).
} 
For our study, we combine personal and household data, clustered at the household level. Since not all of the variables of interest have been gathered since the beginning of the survey in 1986, we only investigate data from the period between 1996 and 2014. People residing in institutions such as retirement homes or student dormitories typically have no influence on how the heating system is operated. We therefore exclude these observations, which results in a main sample of 163,168 observations from 30,033 households in an unbalanced panel.

As the fuel type used for heating can only be observed for the waves of 1998 and 2003 of the sample, we do not include this variable in our estimations. Furthermore, the survey only monitors the expenditures of households for heating and hot water, but not their actual consumption or the prices they face. As a proxy for the price of space heating, we use the real consumer gas price, taken from BMWi (2016). ${ }^{4}$ As of 2010, nearly half of all households in Germany use gas for heating (Federal Statistical Office, 2012). Table 1 shows the relative shares of heating sources for German households in different years.

Table 1: Heating sources in German households, in \%

\begin{tabular}{ccccccc}
\hline \hline Year & Natural gas & Heating oil & District heating & Electricity & Renewables & Other \\
\hline 1998 & 43.25 & 33.97 & 13.10 & 4.62 & 1.13 & 3.94 \\
2002 & 47.69 & 31.82 & 13.68 & 4.10 & 0.99 & 1.73 \\
2006 & 48.56 & 30.15 & 13.24 & 4.04 & 2.98 & 1.02 \\
2010 & 48.61 & 28.12 & 13.13 & 3.96 & 4.35 & 1.82 \\
\hline
\end{tabular}

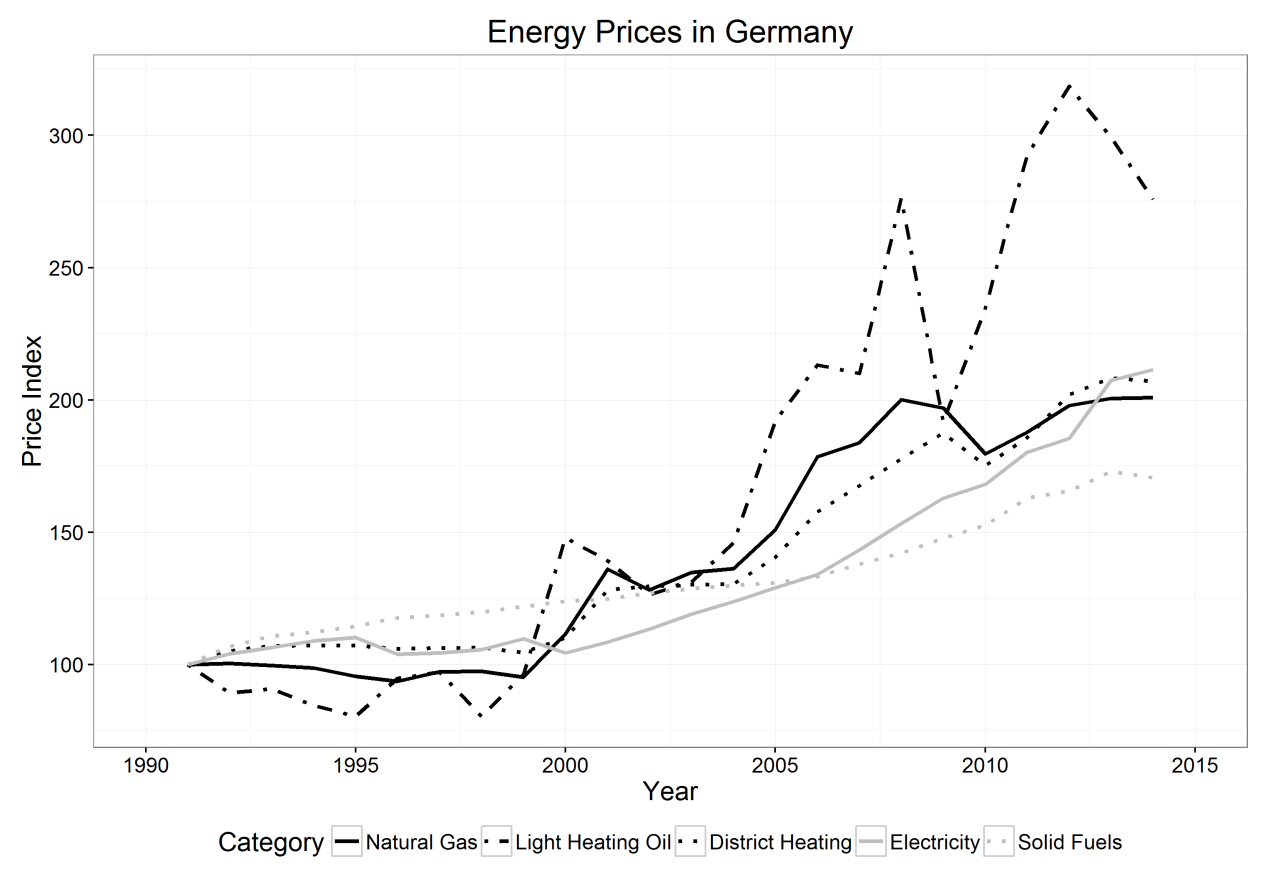

Figure 1: Consumer fuel prices in Germany $(1991=100)$

Figure 1 shows the price development of the most common residential heating fuels in Germany. After a period of stability between 1991 and 1999, heating fuel prices for consumers have increased sharply across energy carriers since 2000. Visual inspection indicates that prices are highly correlated. Expanding on this, Table 2 shows the correlation coefficients

\footnotetext{
4 This approach has also been employed by Dieckhöner (2012), among others.
} 
between the prices of the five main energy carriers used for heating in Germany for the years 1991 to 2013, with coefficients between 0.87 and 0.98 . Including the prices for all five main energy carriers in our regression would therefore result in severe multicollinearity issues. Accordingly, we are confident in using consumer gas prices as our main variable for explaining the price of space heating. In an alternative specification, we also use a price index for energy instead of consumer gas prices in Eurocents as the price variable, which does not significantly affect the results.

We account for regional price variation in two ways: Firstly, we calculate the deviation (in percent) of state-level prices from the federal level for the years 2012-2014. ${ }^{5}$ Due to the lack of state-level data for the rest of our observation period, we assume the differences between states in terms of price during these years to be constant and add or substract the previously calculated respective deviation for the individual states. Secondly, we include state dummies to account for any other variation in prices or other factors between the sixteen federal states in Germany, such as differences in regulatory schemes.

Table 2: Correlation matrix of heating fuel prices

\begin{tabular}{cccccc}
\hline \hline Variable & \multicolumn{1}{c}{ Natural gas } & Heating oil & District heating & Electricity & Wood \\
\hline Natural Gas & 1 & 0.944 & 0.982 & 0.887 & 0.872 \\
Heating Oil & 0.944 & 1 & 0.957 & 0.916 & 0.906 \\
District Heating & 0.982 & 0.957 & 1 & 0.947 & 0.923 \\
Electricity & 0.887 & 0.916 & 0.947 & 1 & 0.896 \\
Wood & 0.872 & 0.906 & 0.923 & 0.896 & 1 \\
\hline
\end{tabular}

For most households, the survey is being conducted in the first quarter of the year, and some of the questions relate to the year before. ${ }^{6}$ Therefore, we add the consumer gas price from the previous year to our dataset (in 2010 terms). Table 3 presents an overview of the selection of variables that we use for our analysis.

\subsection{Descriptive Statistics}

The relevant descriptive statistics of our socio-demographic and technical variables can be seen in Tables 4 and 5. For the person-related variables, we compute the mean of all adult members of the household. An alternative specification would be to only use the data of the household head. However, we assume that heating consumption decisions are usually not only made by the head of the household, but by all (adult) household members.

We include the variables on occupation (FULLTIME, PARTTIME, UNEMPLOYED and RETIRED) to assess whether they also influence expenditures, because some of these groups are likely to spend more hours at home, such as unemployed people (Longhi, 2015). We use the share of all adult members in the household falling into that category, meaning that for any given household, values can range between 0 and 1 . People can also fall into multiple categories if they occupied more than one role over the course of a given year. To account for differences in climate between federal states and years, we include the mean outdoor temperature in January in ${ }^{\circ} \mathrm{C}$ at the state level. Table 6 shows the correlations between selected variables. These correlation coefficients give us a first indication of possible inference between some of the variables. Notably, the expenditures variable shows a comparatively

\footnotetext{
5 Regional price data is taken from Bukold (2015).

${ }^{6}$ Specifically, renters are asked what their average monthly cost of heating is, whereas homeowners are being asked what their cost of heating was in the preceding calendar year.
} 
Table 3: Variable definitions

\begin{tabular}{|c|c|}
\hline Variable & Description \\
\hline $\log \left(\mathrm{EXP} \_\right.$SPACE $)$ & Log of yearly real heating expenditures per square meter, in $€$ \\
\hline $\log \left(\mathrm{EXP} \_\mathrm{CAP}\right)$ & Log of yearly real heating expenditures per inhabitant, in $€$ \\
\hline $\log ($ GASPRICE) & Log of real gas price, in Eurocents per kWh \\
\hline $\log (\mathrm{EPI})$ & Energy price index, $2010=100$ \\
\hline $\log (\mathrm{INCOME})$ & Log of yearly real net household income, in $€$ \\
\hline $\log (\mathrm{SPACE})$ & Log of size of dwelling, in square meters $\left(1 \mathrm{~m}^{2}=10.76 \mathrm{ft}^{2}\right)$ \\
\hline CONDITION & $\begin{array}{l}\text { Condition of home (in good condition, partial renovation, major } \\
\text { renovation, ready for demolition), } 1 \text { or } 0\end{array}$ \\
\hline NEW_WINDOWS & 1 if new windows were installed in the previous year, 0 otherwise \\
\hline NEW_HEAT & 1 if new heating system was installed in the previous year, 0 otherwise \\
\hline TYPE & $\begin{array}{l}\text { Type of building (farm house, single or double house, row/terrace } \\
\text { house or duplex, building containing } 3 \text { to } 4 \text { dwellings, building } \\
\text { containing } 5 \text { to } 8 \text { dwellings, building containing } 9 \text { or more dwellings, } \\
\text { high rise building, other), } 1 \text { or } 0\end{array}$ \\
\hline YEAR & $\begin{array}{l}\text { Vintage class of building (before } 1919,1919-1948,1949-1971, \\
1972-1980,1981-1990,1991-2000,2001-2010,2011 \text { or later), } 1 \text { or } 0\end{array}$ \\
\hline CENTRAL_HEAT & 1 if household has a central heating system, 0 otherwise \\
\hline ADULTS & Number of adults (age 17 or older) in household \\
\hline CHILDREN & Number of children (age 16 or younger) in household \\
\hline OWNER & Owner or tenant of dwelling, 1 or 0 \\
\hline GENDER & Share of male household members (adults only) \\
\hline AGE & Mean age of adult household members \\
\hline GREENS & Share of adult household members who support the Green Party \\
\hline EDUCATION & Mean education level of adult household members, in years \\
\hline FULLTIME & Share of adult household members working full time \\
\hline PARTTIME & Share of adult household members working part time \\
\hline UNEMPLOYED & Share of adult household members registered unemployed \\
\hline RETIRED & Share of adult household members in retirement \\
\hline MEANTEMP & $\begin{array}{l}\text { Daily mean temperature in January (measured at federal state level), } \\
\text { in }{ }^{\circ} \mathrm{C}\end{array}$ \\
\hline STATE & $\begin{array}{l}\text { Federal State (Schleswig-Holstein, Hamburg, Lower Saxony, } \\
\text { Bremen, North Rhine-Westphalia, Hesse, Rhineland-Palatinate, } \\
\text { Baden-Wuerttemberg, Bavaria, Saarland, Berlin, Brandenburg, } \\
\text { Mecklenburg-Western Pommerania, Saxony, Saxony-Anhalt, } \\
\text { Thuringia), } 1 \text { or } 0\end{array}$ \\
\hline
\end{tabular}


Table 4: Summary statistics, economic and socio-demographic variables

\begin{tabular}{lcccc}
\hline \hline Variable & Mean & St. Dev. & Min & Max \\
\hline INCOME & $33,787.410$ & $24,104.270$ & 135.593 & $2,341,463$ \\
GASPRICE & 5.844 & 1.057 & 3.923 & 7.540 \\
EXP_SPACE & 12.587 & 6.940 & 0.005 & 169.583 \\
EXP_CAP & 581.795 & 441.195 & 0.167 & $9,414.025$ \\
ADULTS & 1.991 & 0.811 & 1 & 10 \\
CHILDREN & 0.589 & 0.971 & 0 & 11 \\
OWNER & 0.516 & 0.500 & 0 & 1 \\
GENDER & 0.477 & 0.268 & 0 & 1 \\
AGE & 49.016 & 15.891 & 18 & 100 \\
AGE_SQ & $2,655.057$ & $1,700.534$ & 324 & 10,000 \\
GREENS & 0.051 & 0.197 & 0 & 1 \\
EDUCATION & 12.193 & 2.477 & 7 & 18 \\
FULLTIME & 0.426 & 0.393 & 0 & 1 \\
PARTTIME & 0.146 & 0.274 & 0 & 1 \\
UNEMPLOYED & 0.090 & 0.243 & 0 & 1 \\
RETIRED & 0.271 & 0.417 & 0 & 1 \\
MEANTEMP & 0.58 & 2.51 & -5.2 & 5.7 \\
\hline & & & & \\
\hline
\end{tabular}

Table 5: Summary statistics, technical variables

\begin{tabular}{lcc}
\hline \hline Variable & Mean & St. Dev. \\
\hline SPACE & 104.529 & 45.635 \\
NEW_HEATING & 0.021 & 0.144 \\
NEW_WINDOWS & 0.044 & 0.205 \\
CENTRAL_HEAT & 0.948 & 0.221 \\
CONDITION_1 (In Good Condition) & 0.701 & 0.458 \\
CONDITION_2 (Partial Renovation) & 0.271 & 0.445 \\
CONDITION_3 (Major Renovation) & 0.027 & 0.163 \\
CONDITION_4 (Ready For Demolition) & 0.001 & 0.032 \\
TYPE_1 (Farm House) & 0.028 & 0.166 \\
TYPE_2 (1-2 Fam. House) & 0.367 & 0.482 \\
TYPE_3 (1-2 Fam. Rowhouse) & 0.181 & 0.385 \\
TYPE_4 (Apt. In 3-4 Unit Bldg.) & 0.102 & 0.303 \\
TYPE_5 (Apt. In 5-8 Unit Bldg.) & 0.180 & 0.384 \\
TYPE_6 (Apt. In 9+ Unit Bldg.) & 0.129 & 0.335 \\
TYPE_7 (High Rise) & 0.012 & 0.110 \\
TYPE_8 (Other) & 0.001 & 0.027 \\
Built before 1919 & 0.148 & 0.355 \\
Built 1919-1948 & 0.152 & 0.359 \\
Built 1949-1971 & 0.285 & 0.451 \\
Built 1972-1980 & 0.145 & 0.352 \\
Built 1981-1990 & 0.104 & 0.305 \\
Built 1991-2000 & 0.123 & 0.329 \\
Built 2001 or later & 0.044 & 0.205 \\
\hline
\end{tabular}


strong positive correlation with INCOME, SPACE, and OWNER. Furthermore, INCOME is strongly correlated with a variety of other variables such as SPACE, OWNER, ADULTS, and EDUCATION.

Table 6: Correlation matrix of selected variables

\begin{tabular}{cccccccccc}
\hline \hline Variable & $\log ($ EXP_SPACE $)$ & $\log$ (INCOME) & SPACE & ADULTS & CHILDREN & OWNER & GENDER & AGE & EDUCATION \\
\hline $\log$ (EXP_SPACE) & 1 & -0.131 & -0.296 & -0.061 & -0.100 & -0.131 & -0.036 & 0.100 & -0.060 \\
$\log ($ INCOME) & -0.131 & 1 & 0.528 & 0.464 & 0.206 & 0.303 & 0.149 & -0.174 & 0.408 \\
SPACE & -0.296 & 0.528 & 1 & 0.341 & 0.238 & 0.487 & 0.058 & -0.044 & 0.234 \\
ADULTS & -0.061 & 0.464 & 0.341 & 1 & 0.084 & 0.202 & 0.132 & -0.286 & -0.027 \\
CHILDREN & -0.100 & 0.206 & 0.238 & 0.084 & 1 & 0.013 & 0.017 & -0.417 & 0.066 \\
OWNER & -0.131 & 0.303 & 0.487 & 0.202 & 0.013 & 1 & 0.047 & 0.171 & 0.100 \\
GENDER & -0.036 & 0.149 & 0.058 & 0.132 & 0.017 & 0.047 & 1 & -0.142 & 0.052 \\
AGE & 0.100 & -0.174 & -0.044 & -0.286 & -0.417 & 0.171 & -0.142 & 1 & -0.120 \\
EDUCATION & -0.060 & 0.408 & 0.234 & -0.027 & 0.066 & 0.100 & 0.052 & -0.120 & 1 \\
\hline
\end{tabular}

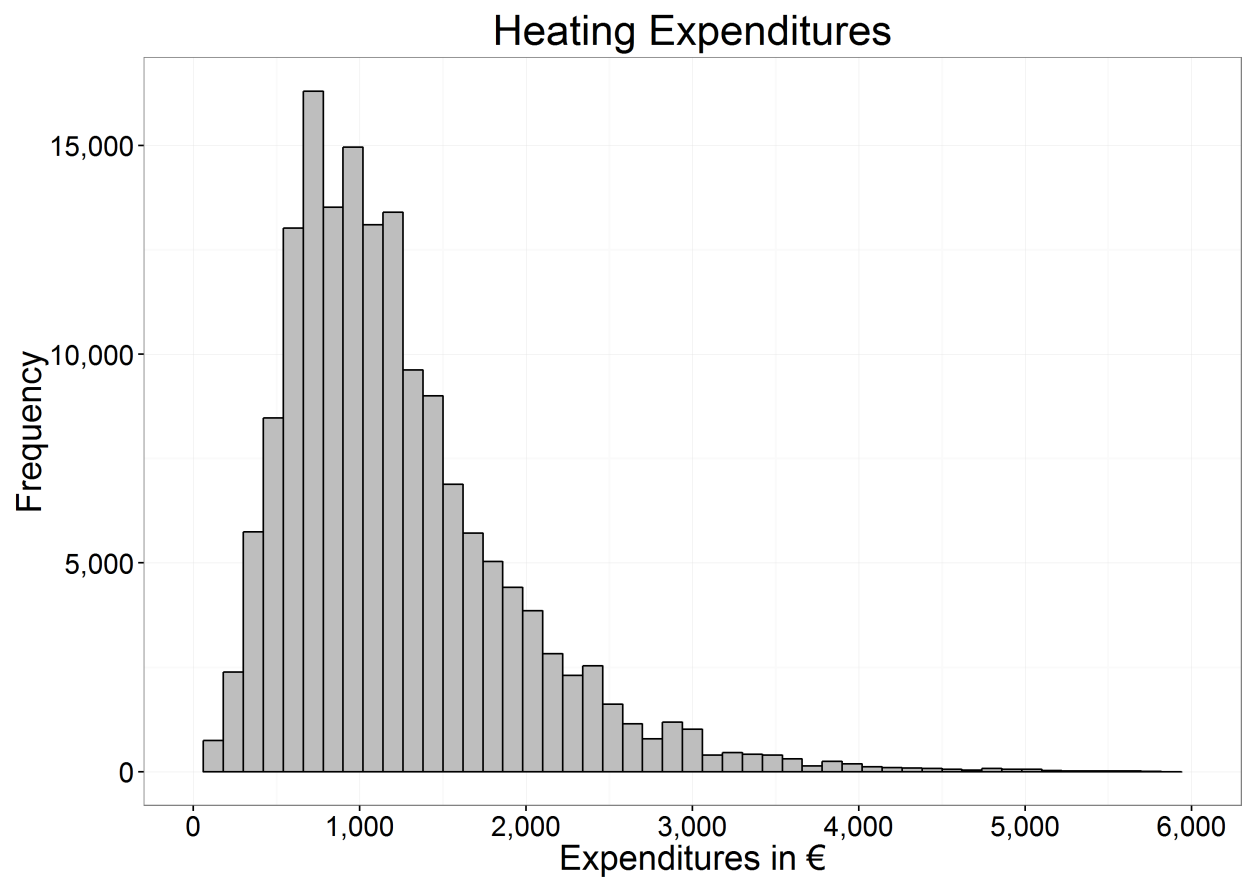

Figure 2: Distribution of heating expenditures per year

Figure 2 depicts the distribution of heating expenditures in 2010 terms among households. ${ }^{7}$ The mean value for yearly real expenditures in our sample is $€ 1,228.96$ with a median of $€ 1,082.74$. Out of the households considered, $99 \%$ spend less than $€ 3,629.51$ per year, or $€ 302.46$ per month, on space heating.

\subsection{Model}

We assume households to maximize their utility from heating and to choose the amount of space heating consumed accordingly. Until 1998, the supply of gas to end consumers in Germany was organized in regional monopolies. Even after liberalization, the option to switch providers appears severely limited. In 2005, consumers who changed providers accounted for

\footnotetext{
7 For the sake of clarity, we omit all observations beyond the $99.95 \%$ quantile in this figure, which eliminates
} 82 out of 163,168 observations. 
only $0.01 \%$ of total gas consumption. ${ }^{8}$ In $2007,0.8 \%$ of private gas consumers decided to switch their provider; in 2014, this ratio increased to 8.4\% (BNetzA, 2015). We therefore assume consumers to be price takers and prices to be exogenous. Given that expenditures are defined as a function of price and consumption, information on consumption choices can be derived by comparing changes in expenditures and prices.

In line with related recent literature (Meier and Rehdanz, 2010; Lange et al., 2014), our model of heating expenditures has the form

$$
\ln \left(E_{i, t}\right)=\beta_{P} \ln \left(P_{i, t}\right)+\beta_{T} T_{i, t}+\beta_{D} D_{i, t}+\beta_{S} S_{i, t}+\gamma_{i}+\epsilon_{i, t}
$$

with $E_{i, t}$ denoting the heating expenditures of household $i$ at time $t, P_{i, t}$ the consumer gas price, $T_{i, t}$ the building characteristics, $D_{i, t}$ the socio-demographic and socio-economic variables, $S_{i, t}$ the state dummies, $\gamma_{i}$ the time-invariant household fixed effects, and $\epsilon_{i, t}$ the error term. Prices, incomes, and expenditures are in 2010 terms.

We use a log-linear specification, regressing on the two measures of expenditures for heating that are most common in the literature: expenditures per square meter of living space and expenditures per capita. We do not equivalize per capita expenditures, meaning that we do not use weights to distinguish between different household members such as adults and children.

Conducting a Hausman test rejects the hypothesis that errors are uncorrelated with the regressors (Hausman, 1978). Therefore, we employ fixed effects at the household level rather than random effects. We cluster several variables at the household level that are presumably time-invariant at the individual level, such as gender or level of education. Using the average for all adult members of the household for these variables instead of only considering the household head results in sufficient year-to-year variation in our sample due to individuals leaving or joining the household in question, rendering a fixed effects approach feasible.

In line with related studies (Baker et al., 1989; Meier and Rehdanz, 2010; Brounen et al., 2012; Lange et al., 2014), we model conditional demand, meaning that we neither observe nor account for possible changes in the appliance stock of the individual household. Instead, we analyze energy behavior given the current equipment stock of the households. In contrast, other researchers have also employed discrete-continuous models, which include both the (discrete) demand for specific appliances and technologies and the (continuous) demand for energy to use them (Vaage, 2000; Nesbakken, 2001; Liao and Chang, 2002). ${ }^{9}$ While this approach potentially allows for a more realistic way to examine interconnected decisions of ownership and consumption, it also makes modeling more complex and requires more detailed data. The resulting elasticities from our estimations should therefore be considered as short term elasticities.

\footnotetext{
8 In the category households and small businesses consuming $300 \mathrm{MWh} /$ year or less. Data from BNetzA (2006).

${ }^{9}$ For a more general microeconomic discussion of the discrete-continuous framework, see Hanemann (1984).
} 


\section{Results}

\subsection{Regression Results}

In the first step of our analysis, we aim at finding determinants of energy expenditures among the technical, economic, and demographic variables at our disposal. Table 7 shows the results of our regression for four model specifications that differ in the dependent variable and in the price variable included. As our dependent variables, we use expenditures per square meter and expenditures per capita. To represent the price of heating, we utilize the consumer gas price in specifications (i) and (iii) and an energy price index in model specifications (ii) and (iv) ${ }^{10}$ We include fixed effects at the household level, but find little variation in those effects across households. In model (i), the mean effect is 3.79 with a standard deviation of 0.42 . The interquartile range is 0.49 .

The price variable has a highly significant influence on expenditures, with values between 0.577 and 0.672. Since our dependent variable is heating expenditures and not heating energy consumption, a value of 1 would correspond to a situation of perfectly inelastic demand, whereas a value of 0 would mean that demand is perfectly elastic. Any value between 0 and 1 would imply relatively inelastic demand, which is the case in our analysis. Two other studies that are directly comparable, given that they also use heating expenditures as their dependent variable, find values between 0.33 and 0.65 for Germany (Rehdanz, 2007) and between 0.36 and 0.83 for Great Britain (Meier and Rehdanz, 2010) across different fuel types and model specifications. When we use a price index for energy instead of the gas price (specifications (ii) and (iv), denoted as EPI), the estimates for the price coefficient are slightly lower, while most of the other coefficient estimates are similar.

The elasticity with respect to expenditures can easily be approximated as a standard price elasticity using the following transformation:

$$
\frac{\partial \ln (E)}{\partial \ln (p)}=\frac{\partial \ln (C)}{\partial \ln (p)}+\frac{\partial \ln (p)}{\partial \ln (p)} \Leftrightarrow \frac{\partial \ln (E)}{\partial \ln (p)}-1=\frac{\partial \ln (C)}{\partial \ln (p)}
$$

where $E$ denotes expenditures for heating, $C$ is heating consumption, and $p$ describes the price of heating. Accordingly, the corresponding price elasticity of heating demand in our estimations ranges from -0.33 to -0.42 .

We find that income elasticity varies from 0.043 to 0.046 when considering heating expenditures per square meter, which is largely consistent with comparable studies. Brounen et al. 2012 report 0.055 for the Netherlands, while Meier and Rehdanz (2010) find values ranging from 0.009 to 0.037 for Great Britain using six different models. For Germany, Rehdanz (2007) finds elasticities between 0.010 and 0.095. For expenditures per capita, the income elasticity is negative in our estimations. Negative values are uncommon, but not unheard of (see e.g. Berkhout et al. 2004). Since we model conditional demand only, the results should be considered as short-term elasticities. In contrast, medium- and long-term income elasticities tend to be higher. Households with increased income are likely to move into larger homes over the medium term, which would increase their heating expenditures as well (Nesbakken, 1999).

\footnotetext{
${ }^{10}$ Specifically, we use the price index for CC045 (electricity, gas and other fuels) in the COICOP classification scheme, which is a weighted combination of the price indices for electricity, gas, liquid fuels, solid fuels, and other fuels (including district heating). Data taken from Federal Statistical Office (2016).
} 
Table 7: Regression Results

\begin{tabular}{|c|c|c|c|c|}
\hline & \multicolumn{2}{|c|}{ Heating expenditures per $m^{2}$} & \multicolumn{2}{|c|}{ Heating expenditures per capita } \\
\hline & (i) & (ii) & (iii) & (iv) \\
\hline $\log ($ GASPRICE) & $0.629^{* * *}(0.013)$ & & $0.672^{* * *}(0.014)$ & \\
\hline $\log (\mathrm{EPI})$ & & $0.577^{* * *}(0.014)$ & & $0.635^{* * *}(0.015)$ \\
\hline $\log (\mathrm{INCOME})$ & $0.043^{* * *}(0.006)$ & $0.046^{* * *}(0.006)$ & $-0.020^{* * *}(0.007)$ & $-0.016^{* *}(0.007)$ \\
\hline $\log (\mathrm{SPACE})$ & $-0.703^{* * *}(0.012)$ & $-0.716^{* * *}(0.012)$ & $0.265^{* * *}(0.012)$ & $0.250^{* * *}(0.012)$ \\
\hline In Good Condition & (base) & (base) & (base) & (base) \\
\hline Partial Renovation & $0.027^{* * *}(0.004)$ & $0.024^{* * *}(0.004)$ & $0.025^{* * *}(0.004)$ & $0.022^{* * *}(0.004)$ \\
\hline Major Renovation & $0.055^{* * *}(0.011)$ & $0.050^{* * *}(0.011)$ & $0.053^{* * *}(0.011)$ & $0.048^{* * *}(0.011)$ \\
\hline Ready For Demolition & $0.110^{* *}(0.049)$ & $0.101^{* *}(0.050)$ & $0.109^{* *}(0.048)$ & $0.099^{* *}(0.049)$ \\
\hline NEW_WINDOWS & $-0.004(0.006)$ & $-0.008(0.006)$ & $-0.007(0.006)$ & $-0.011^{*}(0.006)$ \\
\hline NEW_HEATING & $-0.020^{* *}(0.010)$ & $-0.022^{* *}(0.010)$ & $-0.020^{* *}(0.010)$ & $-0.022^{* *}(0.010)$ \\
\hline Farm $\bar{H}$ ouse & (base) & (base) & (base) & (base) \\
\hline 1-2 Fam. House & $0.039(0.040)$ & $0.041(0.040)$ & $0.039(0.039)$ & $0.042(0.039)$ \\
\hline 1-2 Fam. Rowhouse & $0.005(0.041)$ & $0.005(0.041)$ & $0.006(0.041)$ & $0.006(0.040)$ \\
\hline Apt. In 3-4 Unit Bldg. & $-0.022(0.041)$ & $-0.017(0.041)$ & $-0.016(0.040)$ & $-0.011(0.040)$ \\
\hline Apt. In 5-8 Unit Bldg. & $-0.034(0.041)$ & $-0.028(0.040)$ & $-0.030(0.040)$ & $-0.023(0.040)$ \\
\hline Apt. In $9+$ Unit Bldg. & $-0.081^{*}(0.042)$ & $-0.077^{*}(0.042)$ & $-0.070^{*}(0.041)$ & $-0.066(0.041)$ \\
\hline High Rise & $-0.018(0.055)$ & $-0.026(0.055)$ & $-0.020(0.054)$ & $-0.028(0.054)$ \\
\hline Other & $0.062(0.054)$ & $0.063(0.053)$ & $0.023(0.043)$ & $0.024(0.044)$ \\
\hline Built before 1919 & (base) & (base) & (base) & (base) \\
\hline Built 1919-1948 & $0.007(0.015)$ & $0.008(0.015)$ & $0.007(0.016)$ & $0.007(0.016)$ \\
\hline Built 1949-1971 & $-0.034^{* *}(0.015)$ & $-0.037^{* *}(0.016)$ & $-0.035^{* *}(0.016)$ & $-0.039^{* *}(0.016)$ \\
\hline Built 1972-1980 & $-0.052^{* * *}(0.018)$ & $-0.055^{* * *}(0.018)$ & $-0.055^{* * *}(0.018)$ & $-0.059^{* * *}(0.018)$ \\
\hline Built 1981-1990 & $-0.063^{* * *}(0.021)$ & $-0.068^{* * *}(0.021)$ & $-0.068^{* * *}(0.021)$ & $-0.073^{* * *}(0.021)$ \\
\hline Built 1991-2000 & $-0.118^{* * *}(0.019)$ & $-0.117^{* * *}(0.019)$ & $-0.119^{* * *}(0.019)$ & $-0.119^{* * *}(0.019)$ \\
\hline Built 2001 or later & $-0.296^{* * *}(0.023)$ & $-0.318^{* * *}(0.024)$ & $-0.287^{* * *}(0.024)$ & $-0.314^{* * *}(0.024)$ \\
\hline CENTRAL HEAT & $0.039^{* * *}(0.010)$ & $0.048^{* * *}(0.010)$ & $0.040^{* * *}(0.010)$ & $0.049^{* * *}(0.010)$ \\
\hline ADULTS & $0.063^{* * *}(0.005)$ & $0.039^{* * *}(0.005)$ & $-0.327^{* * *}(0.006)$ & $-0.355^{* * *}(0.006)$ \\
\hline CHILDREN & $0.021^{* * *}(0.004)$ & $0.033^{* * *}(0.004)$ & $-0.319^{* * *}(0.005)$ & $-0.304^{* * *}(0.005)$ \\
\hline OWNER & $0.010(0.007)$ & $0.026^{* * *}(0.007)$ & $0.021^{* * *}(0.007)$ & $0.037^{* * *}(0.007)$ \\
\hline GENDER & $-0.051^{* * *}(0.014)$ & $-0.040^{* * *}(0.014)$ & $-0.056^{* * *}(0.017)$ & $-0.042^{* *}(0.017)$ \\
\hline AGE & $0.007^{* * *}(0.002)$ & $0.004^{* * *}(0.002)$ & $-0.002(0.002)$ & $-0.006^{* * *}(0.002)$ \\
\hline AGE SQ & $-0.00003^{*}(0.00001)$ & $-0.00005^{* * *}(0.00001)$ & $0.0001^{* * *}(0.00001)$ & $0.00003^{* *}(0.00001)$ \\
\hline GREENS & $-0.017^{*}(0.009)$ & $-0.024^{* *}(0.010)$ & $-0.018^{*}(0.010)$ & $-0.025^{* *}(0.010)$ \\
\hline EDUCATION & $0.001(0.003)$ & $-0.002(0.003)$ & $0.001(0.003)$ & $-0.003(0.003)$ \\
\hline FULLTIME & $-0.010(0.007)$ & $-0.009(0.007)$ & $0.010(0.007)$ & $0.012^{*}(0.007)$ \\
\hline PARTTIME & $-0.023^{* * *}(0.007)$ & $-0.025^{* * *}(0.007)$ & $-0.026^{* * *}(0.007)$ & $-0.028^{* * *}(0.007)$ \\
\hline UNEMPLOYED & $0.013^{*}(0.007)$ & $0.018^{* *}(0.007)$ & $-0.0003(0.008)$ & $0.006(0.008)$ \\
\hline RETIRED & $-0.021^{* *}(0.009)$ & $-0.024^{* * *}(0.009)$ & $-0.024^{* *}(0.009)$ & $-0.027^{* * *}(0.009)$ \\
\hline MEANTEMP & $-0.003^{* * *}(0.0004)$ & $-0.004^{* * *}(0.0004)$ & $-0.003^{* * *}(0.0004)$ & $-0.004^{* * *}(0.0004)$ \\
\hline State fixed effects & Yes & Yes & Yes & Yes \\
\hline$N$ & 163,168 & 163,168 & 163,168 & 163,168 \\
\hline $\mathrm{R}^{2}$ & 0.140 & 0.138 & 0.270 & 0.271 \\
\hline Adjusted $\mathrm{R}^{2}$ & 0.114 & 0.113 & 0.221 & 0.221 \\
\hline F Statistic $(\mathrm{df}=50 ; 133085)$ & $432.841^{* * *}$ & $427.259^{* * *}$ & $986.603^{* * *}$ & $987.394^{* * *}$ \\
\hline
\end{tabular}

Notes: ${ }^{* *},{ }^{* *}$, and ${ }^{*}$ indicate significance at the $0.01,0.05$, and 0.10 levels, respectively. Clustered robust standard errors in parentheses. 
Given that in Germany, access to sufficient heating is available to virtually anyone due to social assistance programs, it is not surprising that expenditures do not vary much with income. It appears likely that even low income households are able to fulfill their heating needs to a large extent. Furthermore, high income households presumably have access to better insulation and more efficient heating systems. This would limit their consumption (and therefore expenditures) even if these households were to seek a significantly higher level of thermal comfort. Since we cannot control for measures of efficiency directly, we expect that part of this effect is captured by the income variable, which might have slightly higher coefficients otherwise. We observe the self-assessed condition of the home, which we assume to be at least partially correlated with thermal efficiency. We find the mean household income of people living in a home with the highest condition rating (in good condition) to be $84 \%$ higher than for people living in a dwelling with the lowest level (ready for demolition). This appears to confirm our hypothesis that high income households have access to more energyefficient heating services. Overall, we can confirm that heating is a necessity, rather than a luxury good.

A larger living space corresponds with higher heating expenditures per capita. Naturally, a larger space requires more energy to be heated. Furthermore, in larger homes there are usually more separate rooms that need to be heated. ${ }^{11}$ However, the cost per square meter decreases significantly with an increased dwelling size, which suggests the existence of economies of scale. Due to technical reasons, the type of building is also usually a relevant predictor for heating expenditures. For example, apartments in larger complexes typically require less heating than free standing homes due to excess heat diffusion from adjacent units. We can confirm these findings only for apartment buildings that contain nine or more dwellings, which are associated with lower expenditures. For other categories, however, we do not find significant effects. ${ }^{12}$

We find expenditures to significantly increase with building age. Especially noteworthy is the massive decline in heating costs for buildings constructed since 2001, leading to expenditures that are between $28.7 \%$ and $31.8 \%$ lower compared to the base category. Numerous pieces of legislation that aim to improve the energy efficiency of newly built homes have been introduced over the last three decades, both at the EU and national levels. In Germany, the Energy Savings Ordinance, which was first introduced in 2001 and most recently amended in 2015, commands that all newly constructed buildings fulfill strict efficiency standards (BGBl, 2015). Our results provide evidence for the effectiveness of these rules. However, assessing their economic efficiency would be beyond the scope of this work.

The number of inhabitants has a positive influence on expenditures per square meter, with adults having a slightly stronger effect than children. Per capita expenditures decrease by $27.1 \%$ to $33.0 \%$ per additional household member. The more people live in a household, the higher the chances are that at a specific time during the day, somebody is at home and consumes energy for heating. On the other hand, heating a specific room to a certain temperature requires roughly the same amount of energy regardless of the number of people present, which would explain the significant economies of scale. The evidence from other studies regarding children is mixed: while some researchers find that more children result in higher energy consumption (Hirst et al., 1982; Baker et al., 1989; Meier and Rehdanz, 2010), others report a negative relationship (Rehdanz, 2007). A third group finds the number of

\footnotetext{
${ }^{11}$ Due to the high correlation between the number of rooms and living space, we exclude the former from our estimations. Running an alternative specification including ROOMS and excluding log(SPACE) yields only minimal differences in terms of significance, magnitude, and signs of the coefficients.

${ }^{12}$ Note that the definitions of building categories are not always consistent across different data sources. For example, the SOEP survey does not distinguish between semi-detached and row houses.
} 
children to be insignificant (Nesbakken 1999; Vaage 2000).

Ceteris paribus, homeowners spend slightly more on space heating than tenants. The commonly observed principal-agent problem (see e.g. Allcott and Greenstone 2012; Davis 2012; Gillingham et al. 2012; Levinson and Niemann 2004) for heating efficiency between landlords and tenants would suggest that renters spend more on heating than homeowners. ${ }^{13}$ This does not appear to be the case in our data, which is in line with Meier and Rehdanz (2010). Home ownership is highly correlated with the type of building one resides in. Namely, the rate of ownership for building types 1 to 3, which comprises farm houses and 1- to 2-family homes, is $76.1 \%$. In contrast, for types 4 through 7 , only $18.6 \%$ of residents are owners.

We observe that a larger share of female adults in the household increases expenditures for space heating. According to specifications (i) and (ii), the difference in magnitude between an all-male and an all-female household is roughly equivalent to an additional person living in the household. In the past, researchers in energy economics have seldomly discussed the role of gender in energy use, with the exception of the developing world (Clancy and Roehr, 2003). For industrial countries, Elnakat and Gomez (2015) present one of the few studies that explicitly explore the role of women as household heads. Using survey data from the US, the authors find that female-dominated households use twice as much gas and $54 \%$ more electricity for heating than male-dominated homes. These differences persist at a significant, albeit smaller, level when controlling for dwelling size and other factors (Elnakat and Gomez, 2015). Gender differences in preferences for warmth can also be explained biologically (Kim et al., 1998).

The average age of occupants also has a small positive influence on expenses. Older people, especially once they reach retirement age, tend to spend more time at home than those with full time jobs, which would increase the need for heating. Other studies find the relationship between age and energy use to be non-linear: energy consumption generally increases with age, before declining again after a certain age threshold (Baker et al. 1989; Meier and Rehdanz 2010). We include age squared in the model to test for this possibility. While the variable is significant in specifications (ii) and (iv), the coefficient is very low, indicating that potential non-linear effects are small. There is, however, some additional evidence for this exact relationship in our data: the RETIRED variable, which is highly correlated with average household age and significant in all specifications, has a negative sign. This suggests that expenditures do increase with age, but only up to a certain point, after which they decrease again.

We use the variable GREENS to proxy for environmental consciousness: it indicates the share of adult household members who stated that they support the German Green Party. About $7.5 \%$ of observations have at least one household member who reports supporting the Greens. As our results show, the variable has a significant negative influence on energy expenditures for all four model specifications. Only a small number of studies have explicitly incorporated households' environmental beliefs and attitudes in explaining energy use. While there is some evidence for a negative influence of high environmental conciousness and energy consumption (Sapci and Considine, 2014), others find no significant correlation between expenditures and eco-friendly attitudes and beliefs (Lange et al., 2014).

Regional climatic variation in Germany is relatively low compared to other countries. The mean temperature in January between 1990 and 2016 was $1.11^{\circ} \mathrm{C}$ across German states, with a standard deviation of $2.33^{\circ} \mathrm{C}$. Still, climatic conditions are an important factor in heating

\footnotetext{
${ }^{13}$ The landlord usually has to pay for energy-saving renovations like better insulation or a new, modern heating system, but the tenant then reaps the rewards through a lower heating bill, giving the landlord little incentive to undertake those renovations in the first place.
} 
demand, and a higher average temperature results in lower heating expenditures in our estimations. Additionally, we include state fixed effects to account for further heterogeneity between federal states in terms of climate, prices, and other factors. However, given the lack of significance for the majority of coefficients, these differences appear to be already captured by other variables in our models.

\subsection{Evidence for Heterogeneity between Groups}

In order to quantify the heterogeneity of the determinants of heating demand between different groups of consumers, we employ three distinct methods. Each of these allows us to uncover different facets of heterogeneity in our data: firstly, we utilize interaction terms between the log of the real gas price and seven other explaining variables to reveal differences in price responsiveness between different groups of consumers. Furthermore, we employ quantile regression to obtain information about the relationship between heating expenditures and fuel price at different quantiles of the distribution. Finally, we split the sample into groups of similar households across a number of characteristics using k-means clustering. For the sake of clarity and comparability with other studies in the literature, from now on we focus on the $\log$ of heating expenditures per $\mathrm{m}^{2}$ (specification (i) from Table 7) as our dependent variable.

\subsubsection{Interaction Terms}

Table 8 shows the results for a model specification that includes seven interaction terms. All the explaining variables from Table 7 are still included in the specification, but not all of them are shown in this table for the sake of brevity. All variables that are involved in interactions are mean-centered. We chose these particular interactions to investigate differences in price responsiveness between different socio-demographic groups.

The results show that higher income is associated with higher elasticity of heating expenditures, which corresponds to lower price elasticities in magnitude. Since this paper is the first to investigate this issue, comparisons with previous research are challenging. One comparable study is Madlener and Hauertmann (2011), who find similar results investigating the heterogeneity of rebound effects in residential space heating in Germany. For driving, evidence is mixed: Gillingham (2014) finds that wealthier households react more strongly to price increases, which is the exact opposite of what we find for heating. This can be explained by two factors: firstly, richer households may have more discretionary driving that can easily be avoided. Secondly, wealthy households are more likely to own multiple vehicles, which allows them to switch to the more fuel efficient one when prices increase (Gillingham, 2014). In space heating, these two phenomena seem less relevant. The potential for fuel switching is low, especially in the short term (which is what we consider here), due to the significant costs of installing a new heating system. Discretionary consumption also appears to be less of an issue in heating than in driving: taking into account that the price of heating is relatively low compared to overall income especially for high income consumers, it appears likely that these households simply consume as much heating as they desire, with little regard to costs. Since heating costs represent a more significant share of expenditures for low income households, it seems reasonable to conclude that they pay more attention to price increases for heating, and react more strongly to those increases as a consequence.

The demographic interactions are not statistically significant, indicating that price elasticities do not vary substantially with gender, environmental consciousness, and number of household 
Table 8: Regression results including interaction terms

\begin{tabular}{|c|c|c|}
\hline & \multicolumn{2}{|c|}{ Heating expenditures per $m^{2}$, in $€$} \\
\hline & (i) & (ii) \\
\hline $\log (\mathrm{GASPRICE})$ & $0.514^{* * *}(0.025)$ & $0.629^{* * *}(0.013)$ \\
\hline $\log (\mathrm{INCOME})$ & $0.044^{* * *}(0.006)$ & $0.043^{* * *}(0.006)$ \\
\hline $\log (\mathrm{SPACE})$ & $-0.707^{* * *}(0.012)$ & $-0.703^{* * *}(0.012)$ \\
\hline NEW_WINDOWS & $-0.005(0.006)$ & $-0.004(0.006)$ \\
\hline NEW_HEATING & $-0.022^{* *}(0.010)$ & $-0.020^{* *}(0.010)$ \\
\hline CENTRAL_HEAT & $0.047^{* * *}(0.010)$ & $0.039^{* * *}(0.010)$ \\
\hline ADULTS & $0.064^{* * *}(0.005)$ & $0.063^{* * *}(0.005)$ \\
\hline CHILDREN & $0.027^{* * *}(0.004)$ & $0.021^{* * *}(0.004)$ \\
\hline OWNER & $0.030^{* * *}(0.008)$ & $0.010(0.007)$ \\
\hline GENDER & $-0.056^{* * *}(0.014)$ & $-0.051^{* * *}(0.014)$ \\
\hline AGE & $0.005^{* * *}(0.002)$ & $0.007^{* * *}(0.002)$ \\
\hline AGE_SQ & $-0.00001(0.00002)$ & $-0.00003^{*}(0.00001)$ \\
\hline GREENS & $-0.019^{* *}(0.010)$ & $-0.017^{*}(0.009)$ \\
\hline FULLTIME & $-0.010(0.007)$ & $-0.010(0.007)$ \\
\hline PARTTIME & $-0.023^{* * *}(0.007)$ & $-0.023^{* * *}(0.007)$ \\
\hline EDUCATION & $0.001(0.003)$ & $0.001(0.003)$ \\
\hline UNEMPLOYED & $0.012(0.007)$ & $0.013^{*}(0.007)$ \\
\hline RETIRED & $-0.026^{* * *}(0.009)$ & $-0.021^{* *}(0.009)$ \\
\hline MEANTEMP & $-0.002^{* * *}(0.0004)$ & $-0.003^{* * *}(0.0004)$ \\
\hline $\log (\mathrm{GASPRICE}) * \log (\mathrm{INCOME})$ & $0.100^{* * *}(0.020)$ & \\
\hline $\log ($ GASPRICE $) *$ ADULTS & $0.010(0.015)$ & \\
\hline $\log ($ GASPRICE $) *$ CHILDREN & $0.007(0.012)$ & \\
\hline $\log ($ GASPRICE) $*$ OWNER & $0.195^{* * *}(0.021)$ & \\
\hline $\log ($ GASPRICE $) *$ GENDER & $0.022(0.038)$ & \\
\hline $\log (\mathrm{GASPRICE}) *$ AGE & $-0.001(0.001)$ & \\
\hline $\log ($ GASPRICE $) *$ GREENS & $0.015(0.045)$ & \\
\hline Building type effects & Yes & Yes \\
\hline Building condition effects & Yes & Yes \\
\hline Building age effects & Yes & Yes \\
\hline State fixed effects & Yes & Yes \\
\hline$N$ & 163,168 & 163,168 \\
\hline $\mathrm{R}^{2}$ & 0.142 & 0.140 \\
\hline Adjusted $\mathrm{R}^{2}$ & 0.116 & 0.114 \\
\hline F Statistic & $\begin{array}{l}387.392^{* * *} \\
(\mathrm{df}=57 ; 133078)\end{array}$ & $\begin{array}{l}432.841^{* * *} \\
(\mathrm{df}=50 ; 133085)\end{array}$ \\
\hline
\end{tabular}

Notes: ${ }^{* *},{ }^{* *}$, and ${ }^{*}$ indicate significance at the $0.01,0.05$, and 0.10 levels, respectively. Clustered robust standard errors in parentheses. Column (ii) reproduces column (i) from Table 7 for comparison. 
members. While our analysis in section 3.1 shows that male-dominated households spend less on heating than those with more female inhabitants, there is no significant difference between men and women regarding their price elasticity. In contrast, the interaction between price and owner is statistically significant and relatively large in magnitude. Specifically, homeowners react less strongly to price changes than renters. This effect, which also confirms previous findings by Madlener and Hauertmann (2011), might be driven at least partially by the fact that homeowners usually have higher incomes than tenants.

\subsubsection{Quantile Regression}

To uncover additional details about our sample, we employ a quantile regression approach, again regressing on the logarithm of heating expenditures per square meter of living space. While standard OLS regressions estimate the conditional mean of the distribution, quantile regression allows us to derive coefficients at different quantiles of the distribution of the dependent variable (Koenker and Bassett, 1978). Therefore, we can discover whether households who spend more on heating react differently to price changes compared to those who consume less. Making use of the panel structure of our data, we also include household fixed effects following the methodology laid out in Koenker (2004). Table 9 shows the results for the quantile regression at the $0.1,0.3,0.5,0.7$, and 0.9 quantiles of logged heating expenditures per $m^{2}$ of living space.

Table 9: Quantile regression results, full sample

\begin{tabular}{|c|c|c|c|c|c|}
\hline Variable & $\begin{array}{l}Q_{10} \\
\text { (i) }\end{array}$ & $\begin{array}{l}Q_{30} \\
\text { (ii) }\end{array}$ & $\begin{array}{l}Q_{50} \\
\text { (iii) }\end{array}$ & $\begin{array}{l}Q_{70} \\
\text { (iv) }\end{array}$ & $\begin{array}{l}Q_{90} \\
(\mathrm{v})\end{array}$ \\
\hline $\log$ (GASPRICE) & $0.649^{* * *}(0.015)$ & $0.637^{* * *}(0.011)$ & $0.621 * * *(0.011)$ & $0.620^{* * *}(0.011)$ & $0.632 * * *(0.015)$ \\
\hline $\log (\mathrm{INCOME})$ & $0.105^{* * *}(0.008)$ & $0.099^{* * *}(0.006)$ & $0.096^{* * *}(0.005)$ & $0.090^{* * *}(0.006)$ & $0.098^{* * *}(0.007)$ \\
\hline $\log (\mathrm{SPACE})$ & $-0.535^{* * *}(0.013)$ & $-0.532^{* * *}(0.010)$ & $-0.536^{* * *}(0.009)$ & $-0.551^{* * *}(0.009)$ & $-0.589^{* * *}(0.011)$ \\
\hline NEW_WINDOWS & $-0.026^{* *}(0.013)$ & $-0.014^{*}(0.008)$ & $0.006(0.007)$ & $0.023^{* * *}(0.008)$ & $0.013(0.010)$ \\
\hline NEW_HEATING & $-0.051^{* *}(0.020)$ & $-0.013(0.011)$ & $0.004(0.010)$ & $0.012(0.011)$ & $0.035^{* *}(0.014)$ \\
\hline CENTRAL_HEAT & $0.243^{* * *}(0.018)$ & $0.151^{* * *}(0.013)$ & $0.108^{* * *}(0.009)$ & $0.087^{* * *}(0.009)$ & $0.064^{* * *}(0.012)$ \\
\hline ADULTS & $0.069^{* * *}(0.005)$ & $0.056^{* * *}(0.003)$ & $0.052^{* * *}(0.003)$ & $0.049^{* * *}(0.003)$ & $0.042^{* * *}(0.004)$ \\
\hline CHILDREN & $0.010^{* * *}(0.004)$ & $0.010^{* * *}(0.003)$ & $0.010^{* * *}(0.002)$ & $0.013^{* * *}(0.003)$ & $0.016^{* * *}(0.003)$ \\
\hline OWNER & $-0.103^{* * *}(0.008)$ & $-0.056^{* * *}(0.006)$ & $-0.045^{* * *}(0.006)$ & $-0.034^{* * *}(0.006)$ & $-0.030 * * *(0.008)$ \\
\hline GENDER & $-0.094^{* * *}(0.014)$ & $-0.058^{* * *}(0.009)$ & $-0.034^{* * *}(0.008)$ & $-0.025^{* * *}(0.008)$ & $-0.013(0.010)$ \\
\hline $\mathrm{AGE}$ & $0.012^{* * *}(0.001)$ & $0.008^{* * *}(0.001)$ & $0.006^{* * *}(0.001)$ & $0.004^{* * *}(0.001)$ & $0.002^{* *}(0.001)$ \\
\hline AGE_SQ & $-0.0001^{* * *}(0.00001)$ & )$-0.00004^{* * *}(0.00001)$ & $-0.00002^{* *}(0.00001)$ & $-0.00001(0.00001)$ & $0.00001(0.00001)$ \\
\hline GREĒNS & $-0.071^{* * *}(0.016)$ & $-0.077^{* * *}(0.010)$ & $-0.069^{* * *}(0.010)$ & $-0.060^{* * *}(0.011)$ & $-0.066^{* * *}(0.014)$ \\
\hline EDUCATION & $0.001(0.002)$ & $-0.0001(0.001)$ & $0.001 *(0.001)$ & $0.002^{* * *}(0.001)$ & $0.001(0.001)$ \\
\hline FULLTIME & $-0.056^{* * *}(0.011)$ & $-0.041^{* * *}(0.008)$ & $-0.026^{* * *}(0.007)$ & $-0.015^{*}(0.008)$ & $-0.005(0.009)$ \\
\hline PARTTIME & $-0.034 * * *(0.011)$ & $-0.036 * * *(0.008)$ & $-0.044^{* * *}(0.007)$ & $-0.032^{* * *}(0.008)$ & $-0.018^{*}(0.011)$ \\
\hline UNEMPLOYED & $0.059 * * *(0.012)$ & $0.050 * * *(0.007)$ & $0.046 * * *(0.008)$ & $0.041^{* * *}(0.008)$ & $0.047 * * *(0.011)$ \\
\hline RETIRED & $-0.050^{* * *}(0.016)$ & $-0.038^{* * *}(0.011)$ & $-0.026^{* * *}(0.010)$ & $-0.026^{* * *}(0.010)$ & $-0.008(0.012)$ \\
\hline MEANTEMP & $-0.003^{* * *}(0.001)$ & $-0.003^{* * *}(0.001)$ & $-0.002^{* * *}(0.001)$ & $-0.002^{* * *}(0.001)$ & $-0.001(0.001)$ \\
\hline Constant & $1.378^{* * *}(0.091)$ & $2.083^{* * *}(0.062)$ & $2.472^{* * *}(0.059)$ & $2.909^{* * *}(0.067)$ & $3.427^{* * *}(0.074)$ \\
\hline Building type effects & Yes & Yes & Yes & Yes & Yes \\
\hline Building condition effects & Yes & Yes & Yes & Yes & Yes \\
\hline Building age effects & Yes & Yes & Yes & Yes & Yes \\
\hline State fixed effects & Yes & Yes & Yes & Yes & Yes \\
\hline$N$ & 163,168 & 163,168 & 163,168 & 163,168 & 163,168 \\
\hline
\end{tabular}

Notes: ${ }^{* *}, * *$, and ${ }^{*}$ indicate significance at the $0.01,0.05$, and 0.10 levels, respectively. Clustered robust standard errors are in parentheses, calculated via bootstrap methods.

While most of our coefficients are highly statistically significant, they are also relatively stable between quantiles. Notably, additional income raises expenditures slightly less for households that already spend comparatively high amounts on space heating. Similarly to previous works that found the same result for driving (Wadud et al., 2010; Gillingham, 2014), this might be due to the fact that those households already achieve their preferred level of thermal comfort. Subsequently, they do not increase their consumption as much when their income increases, 
compared to households that spend less on space heating in the first place.

When comparing the price elasticities at the different quantiles, the price response is slightly weaker for households that are in the highest decile in terms of expenditures. The coefficient at the median, depicted in model (iii), is very close to the mean result when compared to specification (i) from table 7 (0.621 as opposed to 0.629). The results show that many of the coefficients are smaller in magnitude at the higher end of the distribution, with some of them becoming statistically insignificant as well. This is compensated by a larger intercept for the higher quantiles. Our finding suggests that households at higher quantiles spend more due to factors that we do not observe, which are then captured by higher coefficients for the fixed effects at the household level. In contrast with our previous results, we find that homeowners spend less on heating in this specification, compared to renters.

\subsubsection{Means Clustering}

Means clustering is a statistical technique to separate data into groups of similar observations (Forgy, 1965). Specifically, k-means clustering splits the $n$ observations in the data set into $k$ groups. The researcher chooses the number of groups and the variables on which to cluster. Initial group means are chosen at random. Then, observations are assigned to those groups in order to minimize the sum of squared differences between every observation and the nearest mean. Usually, the Euclidean distance is used as the measure for the sum of squares. Afterwards, new group means are chosen, if necessary. Observations are then reassigned to different clusters if it improves the solution. This process is iterated until a stable equilibrium is reached.

In principle, any combination of variables can be used to cluster. For this analysis, we utilize age and income as two of the main indicators by which households are often classified into socio-economic groups. Before clustering, we z-standardize both variables. Since the clustering uses the Euclidean distance between observations, variables with higher variation have a stronger impact on group composition. In our case, the clustering would be almost entirely driven by variation in income if we did not standardize the variables. Generally, a higher number of groups allows for more exact clustering as it reduces the sum of squared differences in the sample. On the other hand, having too many groups can result in group sizes that are too small for meaningful estimations. As a compromise between these factors, we use five groups. After assigning each observation to a group, we proceed using the nonstandardized values for income and age for clarity and comparability. The summary statistics for the groups are reported in Table 10. Even after z-standardizing income and age, there is still one group comprised of high income households that is significantly smaller than the other ones. Table 11 shows the results for our preferred specification, estimated separately for the five subgroups.

Groups 1 to 3 are similar in income, but differ substantially in average household age. The estimated coefficients for the price variable range from 0.519 to 0.567 for these groups, while it is significantly higher for group 4. These values correspond to price elasticities between -0.283 and -0.477 for the four groups. It appears that group 5 is too small to derive any meaningful results; for the sake of completeness, we still include it in our table. 
Table 10: Group means

\begin{tabular}{|c|c|c|c|}
\hline Statistic & Mean & St. Dev. & $N$ \\
\hline \multicolumn{4}{|c|}{ Group 1: young, low income } \\
\hline AGE & 34.814 & 5.283 & 66,114 \\
\hline INCOME & 29,445 & 10,757 & 66,114 \\
\hline \multicolumn{4}{|c|}{ Group 2: old, low income } \\
\hline AGE & 72.165 & 6.582 & 37,173 \\
\hline INCOME & 23,287 & 10,775 & 37,173 \\
\hline \multicolumn{4}{|c|}{ Group 3: medium age, low income } \\
\hline AGE & 53.412 & 5.712 & 36,111 \\
\hline INCOME & 27,178 & 10,986 & 36,111 \\
\hline \multicolumn{4}{|c|}{ Group 4: medium age, higher income } \\
\hline AGE & 45.562 & 9.881 & 23,392 \\
\hline INCOME & 69,167 & 19,418 & 23,392 \\
\hline \multicolumn{4}{|c|}{ Group 5: medium age, wealthy } \\
\hline AGE & 50.159 & 11.720 & 378 \\
\hline INCOME & 267,930 & 183,767 & 378 \\
\hline
\end{tabular}

Table 11: Regression results for clustered groups

\begin{tabular}{|c|c|c|c|c|c|}
\hline & Group 1 & Group 2 & Group 3 & Group 4 & Group 5 \\
\hline $\log$ (GASPRICE) & $0.567^{* * *}(0.022)$ & $0.519^{* * *}(0.029)$ & $0.535^{* * *}(0.030)$ & $0.717^{* * *}(0.036)$ & $0.083(0.340)$ \\
\hline $\log (\mathrm{INCOME})$ & $0.040^{* * *}(0.010)$ & $0.024(0.017)$ & $0.035^{* * *}(0.013)$ & $0.027(0.021)$ & $-0.045(0.078)$ \\
\hline $\log (\mathrm{SPACE})$ & $-0.695^{* * *}(0.017)$ & $-0.770^{* * *}(0.030)$ & $-0.765^{* * *}(0.026)$ & $-0.755^{* * *}(0.037)$ & $-0.763^{* * *}(0.200)$ \\
\hline NEW_WINDOWS & $-0.017(0.011)$ & $0.007(0.012)$ & $0.013(0.012)$ & $-0.007(0.014)$ & $-0.128^{* *}(0.064)$ \\
\hline NEW_HEATING & $-0.033^{* *}(0.016)$ & $0.003(0.020)$ & $0.004(0.019)$ & $-0.014(0.022)$ & \\
\hline CENTRAL_HEAT & $0.055^{* * *}(0.016)$ & $0.032 *(0.019)$ & $0.026(0.018)$ & $0.022(0.030)$ & \\
\hline ADULTS & $0.075^{* * *}(0.007)$ & $0.028^{*}(0.016)$ & $0.050^{* * *}(0.014)$ & $0.067^{* * *}(0.013)$ & $0.035(0.105)$ \\
\hline CHILDREN & $0.016^{* * *}(0.006)$ & $0.031(0.082)$ & $0.019(0.017)$ & $0.004(0.009)$ & $0.061(0.047)$ \\
\hline OWNER & $-0.028^{* *}(0.011)$ & $0.055^{* * *}(0.017)$ & $0.015(0.015)$ & $-0.017(0.021)$ & $0.220(0.181)$ \\
\hline GENDER & $-0.063^{* * *}(0.023)$ & $-0.021(0.033)$ & $-0.092^{* *}(0.037)$ & $-0.094(0.060)$ & $-0.962^{* * *}(0.342)$ \\
\hline AGE & $0.033^{* * *}(0.008)$ & $0.004(0.013)$ & $0.0005(0.014)$ & $0.010 *(0.006)$ & $-0.053(0.056)$ \\
\hline AGE_SQ & $-0.0003^{* * *}(0.0001)$ & $0.00003(0.0001)$ & $0.00003(0.0001)$ & $-0.0001(0.0001)$ & $0.001(0.001)$ \\
\hline GREĒNS & $-0.015(0.016)$ & $-0.042^{*}(0.024)$ & $0.001(0.018)$ & $-0.021(0.021)$ & $0.759^{* * *}(0.220)$ \\
\hline EDUCATION & $0.003(0.004)$ & $-0.001(0.007)$ & $-0.016^{* *}(0.007)$ & $0.007(0.006)$ & $-0.086^{*}(0.051)$ \\
\hline FULLTIME & $-0.027^{* * *}(0.009)$ & $0.040(0.026)$ & $0.0002(0.012)$ & $-0.051^{* *}(0.020)$ & $-0.121(0.213)$ \\
\hline PARTTIME & $-0.022^{* *}(0.009)$ & $-0.026(0.024)$ & $-0.027^{* *}(0.013)$ & $-0.036^{*}(0.019)$ & $-0.251(0.208)$ \\
\hline UNEMPLOYED & $0.003(0.010)$ & $-0.059^{*}(0.033)$ & $0.036^{* * *}(0.012)$ & $-0.003(0.039)$ & \\
\hline RETIRED & $0.066^{*}(0.039)$ & $-0.033^{*}(0.018)$ & $0.002(0.014)$ & $-0.008(0.031)$ & $-0.003(0.205)$ \\
\hline MEANTEMP & $-0.003^{* * *}(0.001)$ & $-0.003^{* * *}(0.001)$ & $-0.004^{* * *}(0.001)$ & $-0.003^{* * *}(0.001)$ & $0.010(0.010)$ \\
\hline Building type effects & Yes & Yes & Yes & Yes & No \\
\hline Building condition effects & Yes & Yes & Yes & Yes & Yes \\
\hline Building age effects & Yes & Yes & Yes & Yes & Yes \\
\hline State fixed effects & Yes & Yes & Yes & Yes & No \\
\hline$N$ & 66,114 & 37,173 & 36,111 & 23,392 & 378 \\
\hline $\mathrm{R}^{2}$ & 0.122 & 0.133 & 0.118 & 0.155 & 0.241 \\
\hline Adjusted $\mathrm{R}^{2}$ & 0.090 & 0.107 & 0.086 & 0.113 & 0.111 \\
\hline F Statistic & $\begin{array}{l}138.431^{* * *} \\
(\mathrm{df}=49 ; 48835)\end{array}$ & $\begin{array}{l}91.471^{* * *} \\
(\mathrm{df}=50 ; 29885)\end{array}$ & $\begin{array}{l}71.769^{* * *} \\
(\mathrm{df}=49 ; 26392)\end{array}$ & $\begin{array}{l}63.868^{* * *} \\
(\mathrm{df}=49 ; 17083)\end{array}$ & $\begin{array}{l}2.413^{* * *} \\
(\mathrm{df}=23 ; 175)\end{array}$ \\
\hline
\end{tabular}

Notes: ${ }^{* *},{ }^{* *}$, and ${ }^{*}$ indicate significance at the $0.01,0.05$, and 0.10 levels, respectively. Clustered robust standard errors in parentheses. Building type and state effects excluded for Group 5 due to multicollinearity issues. 


\subsection{Robustness of Results}

In order to cross-check confirm the significance of our results, we perform a variety of robustness checks. We focus on specification (i) from Table 7, regressing on heating expenditures per $\mathrm{m}^{2}$. Following, among others, Gillingham (2014), we estimate the base model from Table 7 with linear specification for expenditures, income, and price to rule out possible misspecification. Our coefficients state that a price increase of 1 Eurocent increases yearly heating expenditures per $\mathrm{m}^{2}$ by $€ 1.36$. Given the mean natural gas price and heating expenditures, this implies a price elasticity of heating expenditures of 0.646. Considering that this value is similar to the original coefficient depicted in Table 7 (0.629), we conclude that there is no problem of misspecification due to the log-log nature of our model.

$74.7 \%$ of our observations originate from households living in West Germany. While this distribution is roughly representative for the population in Germany, it is conceivable that our results so far are mostly driven by observations from West Germany. Table 12 shows the results for spearate regressions for households from West and East Germany. As one main result, the price coefficient is 0.664 for West Germany and 0.544 for East Germany (including Berlin), which corresponds to price elasticities of -0.336 and -0.456 , respectively. Other differences include the OWNER variable, which is only significant in the east, and GENDER, which is only significant in West Germany. On the other hand, the effects of building vintage, household income, gender, and number of people in the household are similar between regions.

Table 12: Regression Results, separated by region

\begin{tabular}{|c|c|c|}
\hline & $\begin{array}{l}\text { West Germany } \\
\text { (i) }\end{array}$ & $\begin{array}{l}\text { East Germany } \\
\text { (ii) }\end{array}$ \\
\hline $\log ($ GASPRICE) & $0.664^{* * *}(0.016)$ & $0.544^{* * *}(0.025)$ \\
\hline $\log (\mathrm{INCOME})$ & $0.040^{* * *}(0.007)$ & $0.046^{* * *}(0.012)$ \\
\hline $\log (\mathrm{SPACE})$ & $-0.695^{* * *}(0.014)$ & $-0.750^{* * *}(0.022)$ \\
\hline NEW_WINDOWS & $-0.006(0.007)$ & $-0.005(0.011)$ \\
\hline NEW_HEATING & $-0.012(0.011)$ & $-0.048^{* *}(0.020)$ \\
\hline CENTERAL_HEAT & $0.017(0.011)$ & $0.102^{* * *}(0.019)$ \\
\hline ADULTS & $0.061^{* * *}(0.006)$ & $0.061^{* * *}(0.010)$ \\
\hline CHILDREN & $0.020^{* * *}(0.005)$ & $0.024^{* * *}(0.009)$ \\
\hline OWNER & $-0.0001(0.008)$ & $0.048^{* * *}(0.015)$ \\
\hline GENDER & $-0.050^{* * *}(0.017)$ & $-0.043(0.027)$ \\
\hline AGE & $0.004^{* *}(0.002)$ & $0.016^{* * *}(0.003)$ \\
\hline AGE_SQ & $0.00001(0.00002)$ & $-0.0001^{* * *}(0.00003)$ \\
\hline GREĒNS & $-0.017(0.010)$ & $-0.013(0.024)$ \\
\hline EDUCATION & $-0.002(0.003)$ & $0.006(0.006)$ \\
\hline FULLTIME & $-0.016^{* *}(0.008)$ & $-0.003(0.013)$ \\
\hline PARTTIME & $-0.015^{* *}(0.008)$ & $-0.041^{* * *}(0.014)$ \\
\hline UNEMPLOYED & $0.018^{* *}(0.009)$ & $-0.005(0.012)$ \\
\hline RETIRED & $-0.019^{*}(0.010)$ & $-0.032^{*}(0.018)$ \\
\hline MEANTEMP & $-0.002^{* * *}(0.001)$ & $-0.005^{* * *}(0.001)$ \\
\hline Building type effects & Yes & Yes \\
\hline Building condition effects & Yes & Yes \\
\hline Building age effects & Yes & Yes \\
\hline State fixed effects & Yes & Yes \\
\hline$N$ & 121,864 & 41,304 \\
\hline $\mathrm{R}^{2}$ & 0.144 & 0.137 \\
\hline Adjusted $\mathrm{R}^{2}$ & 0.116 & 0.114 \\
\hline F Statistic & $\begin{array}{l}376.127^{* * *} \\
(\mathrm{df}=44 ; 98542)\end{array}$ & $\begin{array}{l}139.690^{* * *} \\
(\mathrm{df}=39 ; 34278)\end{array}$ \\
\hline
\end{tabular}

respectively. 'Clustered robust standard errors in parentheses. 


\section{Conclusions and Outlook}

In this study, we investigate possible determinants of space heating expenditures for households via a fixed effects framework. We put the emphasis on including social characteristics which, in this research area, are not as well explored as technical variables. Our analysis yields evidence that both technical variables, most notably building age and dwelling size, as well as some socio-demographic aspects, especially income, age, and gender, are important factors for explaining household expenditures for heating.

In addition, our analysis provides empirical evidence for the existence of some heterogeneity between socio-economic groups. Most notably, wealthier occupants react less strongly to price changes than those with lower incomes. For other demographic variables such as gender and number of household members, however, we find no evidence for differences in price responsiveness. On the other hand, the quantile regression approach shows that the absolute differences in price responsiveness are relatively low between groups across the distribution, which is also true for the other influencing variables that we considered.

Our results have implications for policy makers who attempt to target consumer behavior. The data indicate that consumer reactions to certain policy measures, such as mandatory efficiency standards or subsidies for retrofitting homes, would create divergent results for different groups of consumers. Subsequently, tailoring programs to specific groups might be a better choice than uniform legislation for the entire population. For example, the effectiveness of price-based measures, such as Pigouvian taxation of energy use, critically depends on the magnitude of the price response, which our results show to vary significantly between groups.

We find clear evidence that stricter energy efficiency standards for new buildings have a significant negative impact on heating expenditures, which appears to make this a very effective measure. However, we can not allude to its efficiency, given that we cannot observe the exact building quality, and neither the costs that are incurred as a result. Furthermore, we do not observe the counterfactual scenario of having no building standards, since the additional savings might also stem from endogenous technological progress.

While some effects are hard to mitigate by policy alone, they should still be taken into account when projecting future energy demand. For instance, we find that there are sizable economies of scale in terms of the number of inhabitants of a dwelling. This means that the rising number of single-person households could result in an unexpected increase in overall energy consumption if those effects are not taken into account. While policy measures that coerce people into living in multi-person households seem hardly feasible, this phenomenon should nevertheless be considered when projecting future energy use. Furthermore, our analysis shows that single-person households show the strongest price reactions, which would increase the effectiveness of price-based measures for this particular group. On the other hand, the current trend towards urbanization, which leads to more multi-unit homes and apartment buildings instead of free standing homes, can result in the opposite effect and decrease total energy use. More generally, our results show the complex nature of both the determinants of space heating consumption itself as well as the interaction between price reaction and other factors.

There are several avenues for future research that arise from this work. Utilizing actual energy consumption data as well as observing the fuel type and heating system used by households would likely yield additional insights and allow to compare our results more easily with other studies that investigate household demand for energy. Another possible extension would be 
the estimation of welfare effects for price changes as well as different policy measures that directly or indirectly influence energy prices. More detailed data regarding the insulation of homes as well as the efficiency of the heating systems used could also be valuable, for example in trying to estimate direct rebound effects in space heating.

\section{Acknowledgments}

The authors would like to thank conference participants at the International Rebound Workshop in Aachen, Germany (March 2015), the Spring Meeting of Young Economists in Ghent, Belgium (May 2015), and the RGS Doctoral Conference in Bochum, Germany (February 2016) for helpful feedback, in particular Manuel Frondel and Stephan Sommer. Furthermore, we thank Tugba Atasoy, Julius Frieling, Veronica Galassi, Christian Oberst, and Stefanie Wolff for constructive comments and criticism. Financial support by the Ministerium für Innovation, Wissenschaft und Forschung of North Rhine-Westphalia (MIWF NRW, grant number W 036C) is gratefully acknowledged.

\section{References}

Allcott, Hunt and Michael Greenstone, "Is There an Energy Efficiency Gap?," Journal of Economic Perspectives, 2012, 26 (001), 3-28.

Baker, Paul, Richard Blundell, and John Micklewright, "Modelling Household Energy Expenditures Using Micro-Data," The Economic Journal, 1989, 99 (397), 720-738.

Berkhout, Peter H.G., Ada Ferrer i Carbonell, and Jos C. Muskens, "The ex post impact of an energy tax on household energy demand," Energy Economics, 2004, 26 (3), $297-317$.

BGBl, "Verordnung über energiesparenden Wärmeschutz und energiesparende Anlagentechnik bei Gebäuden (Energieeinsparverordnung - EnEV)," 2015.

BMWi, "Fourth "Energy Transition" Monitoring Report - Summary," 2015.

_ , "Energiedaten: Gesamtausgabe," 2016.

BNetzA, "Monitoringbericht 2006," 2006.

_ , "Monitoring Report 2015," 2015.

Brounen, Dirk, Nils Kok, and John M. Quigley, "Residential energy use and conservation: Economics and demographics," European Economic Review, 2012, 56 (5), 931-945.

Bukold, Steffen, "Gaspreise 2014 \& 2015 - Höhere Margen zulasten der Verbraucher," EnergyComment Global Energy Briefing, 2015, $10 \%$.

Clancy, Joy and Ulrike Roehr, "Gender and energy: is there a Northern perspective?," Energy for Sustainable Development, 2003, 7 (3), 44-49.

Davis, Lucas W., "Evaluating the Slow Adoption of Energy Efficient Investments: Are Renters Less Likely to Have Energy Efficient Appliances?," in Don Fullerton and Catherine Wolfram, eds., The Design and Implementation of U.S. Climate Policy, Chicago (USA): University of Chicago Press, 2012, pp. 301-316. 
Dieckhöner, Caroline, "Does subsidizing investments in energy efficiency reduce energy consumption? Evidence from Germany," SOEPpapers on Multidisciplinary Panel Data Research, 2012, (527).

Elnakat, Afamia and Juan D. Gomez, "Energy engenderment: An industrialized perspective assessing the importance of engaging women in residential energy consumption management," Energy Policy, 2015, 82, 166-177.

Eurostat/SILC, "Distribution of population by tenure status, type of household and income group, code ilc_lvho02," 2015.

Federal Statistical Office, "Mikrozensus - Zusatzerhebung 2010. Bestand und Struktur der Wohneinheiten, Wohnsituation der Haushalte," 2012.

_, "Consumer price index: Germany, years, individual consumption by purpose (COICOP 2-4-digit hierarchy), code 61111-0003," 2016.

Forgy, E. W., "Cluster analysis of multivariate data: efficiency versus interpretability of classifications," Biometrics, 1965, 21 (3), 768-769.

Frondel, Manuel, Nolan Ritter, and Colin Vance, "Heterogeneity in the rebound effect: Further evidence for Germany," Energy Economics, 2012, 34 (2), 461-467.

Galassi, Veronica and Reinhard Madlener, "Some Like it Hot: The Role of Environmental Concern and Comfort Expectations in Energy Retrofit Decisions," FCN Working Paper, 2016, 2016 (11).

Gillingham, Kenneth, "Identifying the elasticity of driving: Evidence from a gasoline price shock in California," Regional Science and Urban Economics, 2014, 47, 13-24.

_ , Alan Jenn, and Inês M.L. Azevedo, "Heterogeneity in the response to gasoline prices: Evidence from Pennsylvania and implications for the rebound effect," Energy Economics, 2015, 52, S41-S52.

_ , Matthew Harding, and David Rapson, "Split Incentives in Residential Energy Consumption," The Energy Journal, 2012, 33 (2), 37-62.

Hanemann, W. Michael, "Discrete/Continuous Models of Consumer Demand," Econometrica, 1984, 52 (3), 541-561.

Hausman, J. A., "Specification Tests in Econometrics," Econometrica, 1978, 46 (6), 1251.

Hirst, Eric, Richard Goeltz, and Janet Carney, "Residential energy use," Energy Economics, 1982, 4 (2), 74-82.

Hlavac, Marek, stargazer: Well-Formatted Regression and Summary Statistics Tables Harvard University 2015. R package version 5.2.

Kim, Han, Clark Richardson, Jeanette Roberts, Lisa Gren, and Joseph L. Lyon, "Cold hands, warm heart," The Lancet, 1998, 351 (9114), 1492.

Koenker, Roger, "Quantile regression for longitudinal data," Journal of Multivariate Analysis, 2004, 91 (1), 74-89.

- and Gilbert Bassett JR., "Regression Quantiles," Econometrica, 1978, 46 (1), 33-50.

Lange, Ian, Mirko Moro, and Laura Traynor, "Green hypocrisy?: Environmental attitudes and residential space heating expenditure," Ecological Economics, 2014, 107, 76-83. 
Levinson, Arik and Scott Niemann, "Energy use by apartment tenants when landlords pay for utilities," Resource and Energy Economics, 2004, 26 (1), 51-75.

Liao, Huei-Chu and Tsai-Feng Chang, "Space-heating and water-heating energy demands of the aged in the US," Energy Economics, 2002, 24 (3), 267-284.

Longhi, Simonetta, "Residential energy expenditures and the relevance of changes in household circumstances," Energy Economics, 2015, 49, 440-450.

Madlener, Reinhard and Maximilian Hauertmann, "Rebound Effects in German Residential Heating: Do Ownership and Income Matter?," FCN Working Paper, 2011, 2011 (2).

Meier, Helena and Katrin Rehdanz, "Determinants of residential space heating expenditures in Great Britain," Energy Economics, 2010, 32 (5), 949-959.

Nesbakken, Runa, "Price sensitivity of residential energy consumption in Norway," Energy Economics, 1999, 21 (6), 493-515.

_ , "Energy Consumption for Space Heating: A Discrete-Continuous Approach," The Scandinavian Journal of Economics, 2001, 103 (1), 165-184.

Rehdanz, Katrin, "Determinants of residential space heating expenditures in Germany," Energy Economics, 2007, 29 (2), 167-182.

Sapci, Onur and Timothy Considine, "The link between environmental attitudes and energy consumption behavior," Journal of Behavioral and Experimental Economics, 2014, 52, 29-34.

Schuler, Andreas, Christoph Weber, and Ulrich Fahl, "Energy consumption for space heating of West-German households: empirical evidence, scenario projections and policy implications," Energy Policy, 2000, 28 (12), 877-894.

Socio-Economic Panel (SOEP), "Data for years 1984-2014." version 31, SOEP, 2016, doi: 10.5684/soep.v31.

Vaage, Kjell, "Heating technology and energy use: a discrete/continuous choice approach to Norwegian household energy demand," Energy Economics, 2000, 22 (6), 649-666.

Wadud, Zia, Daniel J. Graham, and Robert B. Noland, "Gasoline Demand with Heterogeneity in Household Responses," The Energy Journal, 2010, 31 (1), 47-74.

Wagner, Gert G., Joachim R. Frick, and Jürgen Schupp, "The German SocioEconomic Panel Study (SOEP) - Scope, Evolution and Enhancements," Schmollers Jahrbuch, 2007, 127 (1), 139-169. 